\title{
To measure and what to measure
}

\section{Towards assessing the impact of social crime prevention projects}

\section{CHANDRÉ GOULD \\ Institute for Security Studies \\ cgould@issafrica.org}

The idea that it is necessary to address crime through social development is gaining currency in South Africa. Indeed, in the face of high crime rates that seem not to respond significantly to increases in the number of policemen and women, and in the face of seemingly intractable problems in the criminal justice system, there is a need to determine and address the social causes of crime. In order to convince government, funding institutions and the public that social interventions offer a long-term solution it is necessary to be able to measure their impact. This article describes a social development initiative aimed at preventing and reducing crime in a rural area in the Western Cape. It argues that while it is possible to identify indicators of success, measuring the impact of these kinds of interventions cannot be achieved in the short term. Also, while monitoring and evaluation are important, a balance must be found between allocating resources to core activities, and to monitoring and evaluation.

Hoekwil is a tiny town in the south Western Cape. So tiny, in fact, that you would be hard pressed to find a map that reflects its location. The village is close to the larger town of George and the well-known holiday destination,

Wilderness. Apartheid planning saw to it that, much like every other village or town in South Africa, the majority of residents live in a township, Touwsranten, some 200 metres from the village. Stretching all the way from Hoekwil through the hills and natural forest to Knysna is a farming district that yields vegetable and dairy produce found in Woolworths and Pick n Pay stores from Johannesburg to Cape Town, and even Tescos and Marks and Spencer in the United Kingdom.
In many respects Hoekwil is an unlikely location for a crime reduction initiative, not least because the rate of crime in the area is low by comparison to the more densely populated George and its surrounding townships of Thembalethu, Conville and Pacaltsdorp. Yet 12 months ago some of the most prominent commercial farmers in the area became concerned when the young men and teenage children whose parents labour on their farms started forming gangs. On several occasions these groups of young men engaged in violent fights over weekends and there were rumours that some had firearms. It was feared that unless something was done to change the situation, violent crime would become an entrenched problem. 
An unscientific, but probably fairly accurate analysis of the problem by the farmers led to the conclusion that the problem was boredom - there was not much for young people to do on the farms over the weekends. This, in combination with the alcohol abuse that is common amongst young people and their parents in the area, created fertile conditions for violence to flare up. Initially the farmers thought that if they were to provide the impetus and resources for sports activities over the weekends it would go some way towards alleviating the problem. Twelve months later the youth development programme that has developed from this initial idea is doing a great deal more than that.

\section{The Seven Passes Initiative is now a registered} non-profit organisation operating in the area between the Hoogekraal river and Hoekwil, encompassing some 38 commercial farms, two former state forestry reserves, as well as the residential areas of Hoekwil and Touwsranten. The Initiative is managed by a board made up of farmers, local businessmen, a prominent member of the Touwsranten community, the head of the Dutch Reformed Church in Touwsranten, a representative from Eden Campus (an entrepreneurial school located near the even smaller town of Karatara), and the author of this article, both as a member of the Hoekwil community and as an ISS researcher.

In January 2008 the farmers agreed that a portion of the financial allocation given to them by local government to subsidise their security costs could go towards paying a fulltime co-ordinator for the Initiative. They did this based on the understanding that a social intervention aimed at youth development could have as much, if not more, impact on their security in the long run than policing the problem through increasing the number of guards in the district. The money that became available was sufficient to pay a full-time local co-ordinator. The idea was that the coordinator would ensure that children, particularly those from disadvantaged backgrounds, were engaged in positive activities in the afternoons after school and over weekends and holidays. These activities were intended to include at least sport, drama, and music.
Very early on the board decided that the Initiative should begin by establishing homework clubs for children living on farms and in Touwsranten. It was reasoned that the children living on the farms are, in many cases, unable to turn to their parents for help with their homework, either because their parents are illiterate or because they work long hours and are too tired in the evening to assist them. In the absence of any homework support, the children are unlikely to perform optimally at school, which in turn affects their self-esteem and motivation to pay attention to their schoolwork. It was also quite evident that high levels of alcohol abuse by some of the parents affected their children's ability to cope at school and socially. The homework clubs were identified both as an end in themselves and a way of gathering children together so that they could be involved in other activities.

As an initiative that is aimed at the long and medium-term reduction and prevention of crime and at positive youth development, the challenge has been to establish indicators of success. Indeed, in the context of increased calls for a social development response to the high crime rate in South Africa, projects like this need to be able to show whether in fact they can contribute to making communities, and ultimately society in general, safer. Unless they can show their worth through ongoing monitoring of indicators, it is unlikely that they will attract support in the long run. However, the challenge with any endeavour aimed at bringing about positive social change, and in particular changing behaviour, is that such change takes place slowly and in ways that are hard to measure. Indeed, measurement itself can become expensive, and attract resources away from initiatives themselves.

Some measure of success or failure is essential in order to determine whether allocating resources to these kinds of initiatives, rather than to more traditional forms of crime control, is worthwhile. Yet determining the unit of measurement and the most accurate indicators is no simple matter.

Indeed, while it is vital to ensure that measurement and assessment of activities such as this take place, it is equally important to make 
sure that the process of measurement does not become so burdensome to the implementing organisation that it takes resources away from core activities. In the following section an overview is provided of the relationships that the organisation has established in order to be sustainable, and some of the indicators that have been identified to measure the success of the project.

\section{ALLIANCES AND INDICATORS}

Eden campus is a small post-matric entrepreneurial training centre linked to the Nelson Mandela Metropolitan University. It is located in Karatara, a former forestry settlement that borders on the area covered by the Seven Passes Initiative. Through consultations with the students, who themselves come from disadvantaged communities in the Western Cape, it was agreed that students would make themselves available on a volunteer basis to supervise the homework clubs and assist the children with their homework. Since the beginning of 2008 a handful of students have made themselves available twice a week (on a Tuesday and Thursday evening between 5 and $7 \mathrm{pm}$ ) to supervise homework. They have been transported from Eden campus to two farm halls and a church hall (and later the community hall) in Touwsranten where high school children have gathered to do their homework.

At these locations the children are provided with a light snack (sandwiches or soup). While the feedback received by the Committee suggests that the homework clubs have become an important aspect of some of the children's lives, there were some unforeseen problems. For example:

- The students were not always able to assist the children with homework in certain subjects; particularly those subjects they did not take at school or themselves struggled with. During exam times when the school children should have been receiving extra assistance with their studies, the students were also writing exams and were unable to come to homework clubs
- Although the homework clubs were aimed primarily at high school students, the younger children in Touwsranten started coming to the hall and initially disrupted the classes, as they were noisy and uncontrollable.

This last problem has subsequently been solved by establishing a junior homework class that has, over time, developed even more consistent and diligent participation than the senior clubs. The junior class is managed by volunteers from the Hoekwil and Touwsranten communities.

The problem of students not being able to assist the children in certain subjects has been overcome by forming an alliance with a private school in George. A small number of teachers from this school (Maths and Science teachers in particular) have volunteered to come to one of the farms one afternoon a week to provide extra lessons in the subjects that the students have identified as problematic. Although it took some time for the children to appreciate and take advantage of the service being offered (there were a few weeks when no children arrived for extra lessons), over the past two terms the classes have become more popular and are regularly attended.

What the board has come to realise is that while the homework clubs can assist children who do relatively well at school to do better, they do not assist children who are failing or who have learning difficulties. These children, who appear to be in the majority, require far more intensive and specialised assistance that they are not receiving at school or at home. It has also become clear that children in rural and impoverished communities are at a tremendous disadvantage when it comes to meeting the project-related requirements of the OBE system. In order to complete research projects the children require access to libraries or the Internet, neither of which is readily available. The area co-ordinator therefore spent a great deal of time in the public library copying resource books for the children to use for projects. As helpful as this may be, it points to a failure of the schools and Department of Education to understand the circumstances of learners. As such, the homework clubs themselves 
can provide indicators of where schools are failing.

\section{INDICATOR 1: LEVEL OF PARTICIPATION IN HOMEWORK CLUBS}

Registers are kept of the children who attend homework club. The registers include the name of the child, his or her grade, and remarks about what assistance was required. Through these registers it is possible to assess whether there is regular attendance and when attendance rises or falls. Over the year a small group of children (particularly those who are doing well at school) has regularly attended homework clubs, while others come only when they need particular help.

Although this indicator does not provide any information about the extent to which the Initiative is specifically contributing to crime reduction, the fact that there is a core group of children who attend regularly suggests that the intervention is meeting a need.

\section{INDICATOR 2: SCHOOL ACHIEVEMENT}

In order to monitor the progress of children in the catchment area, the area co-ordinator obtained permission from those learners and their parents to see copies of their quarterly school reports. To get copies of the reports the area co-ordinator had to establish a relationship with all the schools attended by children from the area. In 2008 a number of the children's reports were accessed and scrutinised. Although over time it should be possible to determine whether individual children's marks are increasing or decreasing, it is impossible to directly link the cause of the increase or decrease to homework club participation in the short term. In the long term, however, (over say two or three years) it will be possible to determine trends. If, for example, a significant proportion of homework club members' marks go up or down, it may suggest that the homework clubs have had an effect. The children who do not attend would provide a control group against which results could be measured. In the short term, however, monitoring the results does allow the area co-ordinator to identify whether he needs to intervene, for example by speaking to a child and/or his or her parents about marks that are going down, or by assisting a teenager who is doing well to apply to tertiary institutions.

There are several teenagers whose consistently low marks and low school attendance have alerted the board to problems. A few of these children have extreme learning difficulties that the schools are unable to address. Indeed, given the large number of children who appear to have foetal alcohol spectrum disorders, this is a problem that is likely to continue for many years to come. The fact is that in the absence of state institutions that can provide support in the form of skills training or protected employment, there is very little that can be done to prevent vulnerable teenagers from falling into poverty and unemployment.

\section{INDICATOR 3: CRIME STATISTICS}

For a citizen involved in an initiative like Seven Passes, obtaining regular police statistics is no simple matter. Thus monitoring the local police statistics over a period of time is not as easy as it first may seem, especially since the area covered by the local police station does not correspond neatly to the area covered by the Initiative.

Nevertheless, the fact that a relationship was built between the head of the local police station and the area co-ordinator and members of the board of the Initiative did facilitate the flow of information. In addition, the security company employed by the farmers in the area has a strong and functional relationship with the SAPS and with Seven Passes. The board was thus able to obtain the police statistics to establish a baseline.

However, it soon emerged that many of the crimes that plague the community are not recorded in the statistics. The statistics for example did not, and could not be expected to, provide an indication of the level of violence resulting from the gang activities. That is because in some cases the police 
were not called to respond to the activities, or broke up fights with warnings rather than charging individuals. Indeed, the head of the local police station (Wilderness) told members of the board that although there is a mechanism for recording cases of domestic violence, even those that don't result in any judicial action, drunken assault is not recorded at police station level other than in the notebooks of individual officers and perhaps the Occurrence Book. So these acts, while they certainly have an impact at community level, cannot be monitored through use of police statistics. The following table shows the crimes recorded by the local SAPS between 1 May and 31 July 2008.

Table 1: Police crime stats: 1 May - 31 July 2008

\begin{tabular}{l|c}
\hline Offence & $\begin{array}{c}\text { Total number } \\
\text { of cases }\end{array}$ \\
\hline $\begin{array}{l}\text { Liquor trade, liquor products and } \\
\text { sorghum beer }\end{array}$ & 7 \\
\hline Assault GBH & 9 \\
\hline Burglary at residential premises & 8 \\
\hline $\begin{array}{l}\text { Offences under the Drugs and } \\
\text { Trafficking Act }\end{array}$ & 4 \\
\hline Common assault & 5 \\
\hline $\begin{array}{l}\text { In possession of presumed stolen } \\
\text { property }\end{array}$ & 2 \\
\hline Attempted rape (not wife by & 1 \\
own husband) & 1 \\
\hline Domestic violence & 1 \\
\hline Indecent assault & 2 \\
\hline Theft general & 1 \\
\hline $\begin{array}{l}\text { Unlawful intrusion of premises } \\
\text { with criminal intent }\end{array}$ & 1 \\
\hline Robbery & 1 \\
\hline Murder & \\
\hline Theft from a motor vehicle & \\
\hline Theft of motor vehicle and motor & \\
\hline
\end{tabular}

Source: SAPS: Crime Statistics Analysis, George Blocks 101946, 101945, 101950

\section{INDICATOR 4: POSITIVE PARENTING}

Over time, the Initiative has established a range of activities in collaboration with local government, local sports clubs and other service organisations. During the course of 2008 children in the area have taken part in sailing lessons, first-aid courses, and sports teams (rugby, soccer and netball) have been established. Drama and singing groups have emerged. In the case of these activities records have been maintained, not only of the children's participation but also of their parents' participation in showcase events. The Initiative aims to increase parental involvement in children's lives and thus make a small contribution to encouraging better parenting. Monitoring whether parents increase or decrease their involvement in these kinds of activities will allow an assessment of successes in this area. Once again, change is unlikely to be evident in the short-term.

Other indicators such as a drop in teenage pregnancy rates and an increase in the number of children who apply for and are accepted at universities will also be used to assess the impact of the initiative. Of course, increases in the number of teenage pregnancies would be a warning sign that the programme is not achieving its objectives.

\section{CONCLUSION}

Ongoing monitoring and evaluation (M\&E) of programmes such as the Seven Passes Initiative is vitally important to assess whether they can have an effect on crime rates and social development. Yet few CBOs or NGOs that are project-focused have the skills or the time required for ongoing M\&E. In this case a partnership between a research institute and the $\mathrm{CBO}$ allows for $\mathrm{M} \& \mathrm{E}$ to take place on an ongoing basis at relatively little cost.

It remains to be seen whether Seven Passes will in fact make a long-term difference to the community. At this point the crisis in the world 
economy is already being felt in the farming district with a number of dairy farmers currently having to sell their milk at less than what it costs them to produce it. This has led to job losses in the commercial dairy sector in the area, with more expected to follow. It means that Seven Passes is unlikely to be able to rely on the financial support from commercial agriculture that has kept it afloat for the past year. Ideally local businesses and local government should step in to fill the gap because it is fairly obvious that initiatives such as this are only sustainable in the long term if they have the support and buy-in from people and businesses in the area in which they operate. 